\title{
Is a Mechanic Prosthetic Valve in Tricuspid Position an Absolute Impediment to Implant a Definitive Electrode in the Right Ventricle?
}

Luis Antonio Arabia ${ }^{1, *}$, Juan Carlos Luciano²

\section{ORCID IDs}

Arabia LA (D) https://orcid.org/0000-0003-0673-0234

Luciano JC (D) https://orcid.org/0000-0003-0519-7984

\begin{abstract}
This is the case of a middle-aged woman with Ebstein anomaly, who had a tricuspid valve replacement with a mechanic Starr-Edwards caged-ball valve many years ago, and needed an implantable cardioverter defibrillator (ICD) and ventricular pacing due to ventricular tachycardia and atrioventricular block with syncope. Furthermore, she has a chronic respiratory disease that make open chest surgery inadvisable. Prosthetic valves are a real obstacle to cross them and place catheters in the distal chamber. This report shows a technique to get access to the right ventricle endocardium through the annulus and placing the ICD electrode with correct sensing and pacing.
\end{abstract}

KEYWORDS: Ebstein anomaly; Tricuspid valve; Mechanic valve; Implantable cardioverter defibrillator; Electrode.

1. Clinica Privada del Prado - Córdoba - Argentina.

2. Instituto Oulton - Córdoba - Argentina.

*Corresponding author: luisarabi@hotmail.com

Received: Aug 18, 2020 | Accepted: Sep 17, 2020 


\section{INTRODUCTION}

This is the case of a 59-year-old woman with Ebstein anomaly who had a tricuspid valve replacement with a mechanic Starr-Edwards caged-ball valve in 1975. She had several episodes of syncope, some of them with paroxysmal atrioventricular (AV) block and, in Holter monitoring, nonsustained ventricular tachycardia was seen. Her ejection fraction was $44 \%$ and coronary disease was not seen in the coronariography. The electrophysiologic study was done from the left via retroaortic way and showed a supraventricular irregular rhythm (nonsinus rhythm), with frequent episodes of bradycardia, prolonged His ventricle interval $88 \mathrm{~ms}$ and spontaneous events of AV block. Ventricular stimulation induced multiple morphologies of ventricular tachycardia, so an implantable cardioverter defibrillator (ICD) was indicated but epicardial approach was discarded due to a severe respiratory disease.

\section{TECHNIQUE}

Two left subclavian vein punctures were performed using a steerable decapolar catheter to see the electrograms and help guide the access through the tricuspid annulus. Since the patient has an Ebstein anomaly, the true annulus is not easy to define.

Another anatomic reference was obtained contrasting the coronary sinus using the venous phase by left coronary artery injection (Fig. 1). Initially, an implant of the electrode in the coronary sinus branches was attempted, but it was not possible to get a stable position in any vein. Using a $6 \mathrm{~F}$ multipurpose catheter, a stiff wire was used for the puncture beside the valve annulus and across to the right ventricle (RV) (Fig. 1).

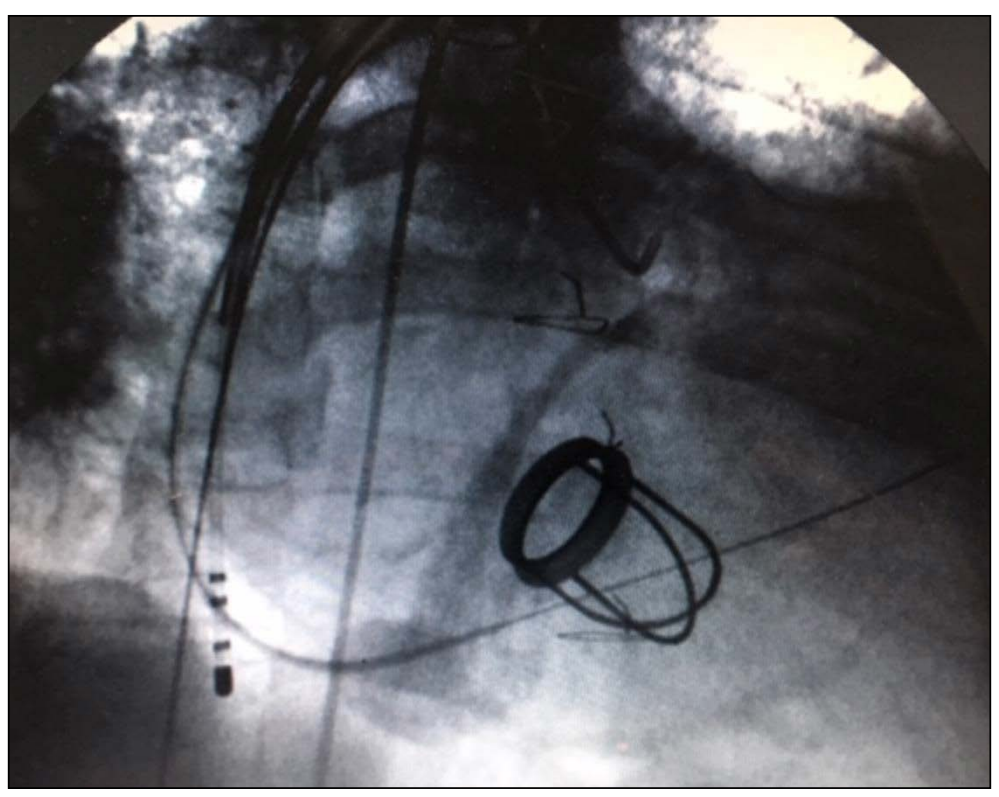

Figure 1. Coronary sinus. Guide wire crossing through the annulus to the RV.

Then, a $5 \times 60 \mathrm{~mm}$ balloon was placed and inflated (Fig. 2), a long peel away sheath (Saint Jude Medical at this moment) (Fig. 3) was advanced into the RV and an active fixation electrode was implanted in its apex (Fig. 4). The rest of the procedure was performed as usual for an ICD implant. No complications were seen neither in the procedure nor within 6 and 12 months of follow up, there were no leaks or valve disfunction. 


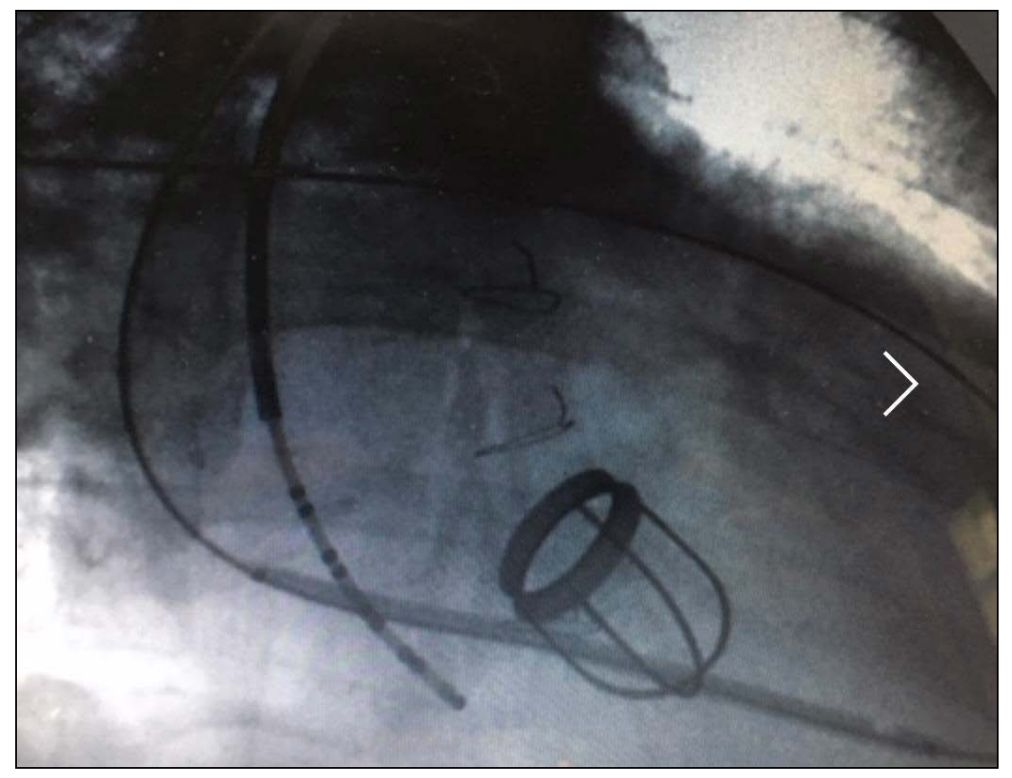

Figure 2. Decapolar catheter. Balloon inflated in the annulus.

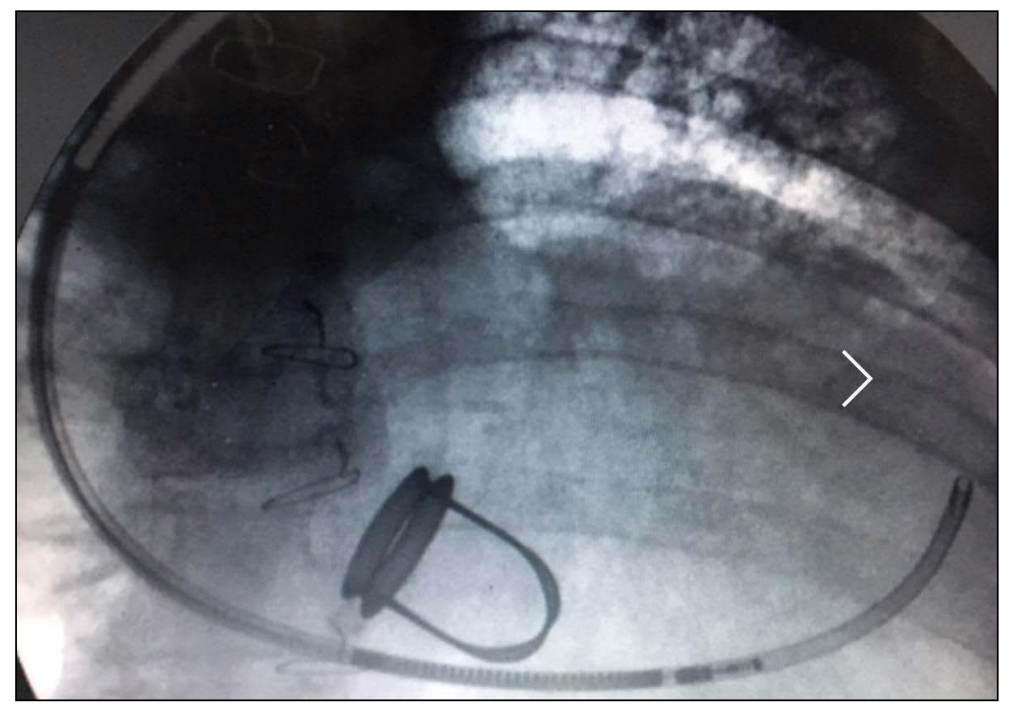

Figure 3. Peel away sheath and ventricular electrode. Left anterior oblique.

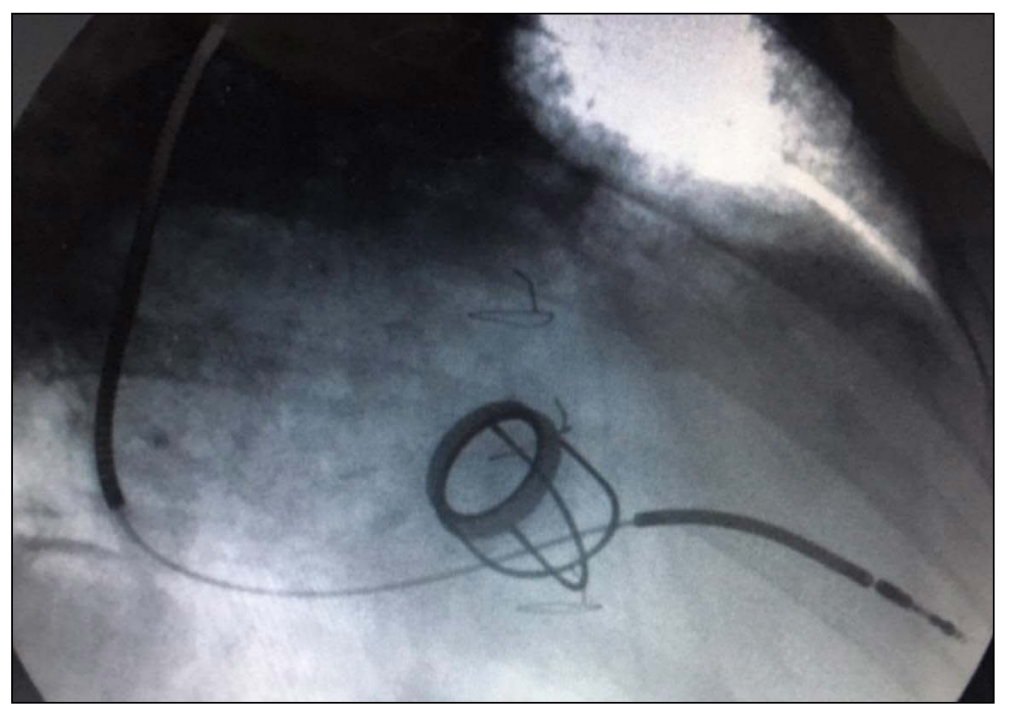

Figure 4. Lead in the RV apex. Right anterior oblique. 


\section{DISCUSSION}

There are few publications about ventricular pacing in patients with mechanical valves in tricuspid position, it is an access barrier to the RV from the right atrium. Almost all of them are case reports and some alternatives are epicardial approach, however, it is not the best option in many patients with prior cardiovascular surgery. Left ventricular pacing through the coronary sinus and His bundle pacing were published ${ }^{1-7}$.

In the case of this study, implantation in the CS was not possible due to electrode instability, severe respiratory disease was a contraindication for open chest surgery and, due to the Ebstein anomaly with the distortion of the AV anatomy, it is difficult to be sure about were His bundle is located.

\section{CONCLUSION}

Ventricular pacing in patients with mechanical valves in tricuspid position are not very frequent but are really challenging and the surgeon has to keep in mind off-label strategies, as presented in this study, to give a safe and trustworthy ventricular pacing.

\section{AUTHOR'S CONTRIBUTION}

Both authors contributed equally to this paper.

\section{REFERENCES}

1. Kumar D, Chakraborty S, Singhi AK. Innovative use of hardware to help cross bioprosthetic tricuspid valve for pacemaker implantation. IHJ Cardiovascular Case Reports (CVCR). 2018;2(3):205-7 https://doi.org/10.1016/j.ihjccr.2018.05.012

2. Schreiber C, Mehmanesch H, Kolb C, Schmitt C, Lange R. Modified implantation of a transvenous defibrillator in a patient after tricuspid valve replacement. Pacing Clin Electrophysiol. 2000;23(11):1698-9. https://doi.org/10.1046/j.1460-9592.2000.01698.x

3. Grimard C, May MA, Mabo P, Babuty D. An original defibrillation lead implantation to avoid tricuspid prosthesis damage. EP Europace. 2010;12(4):589-90. https://doi.org/10.1093/europace/eup392

4. Biffi M, Bertini M, Ziachhi M, Boriani G. Transvenous cardioverter-defibrillator implantation in a patient with tricuspid mechanical prosthesis. J Cardiovasc Electrophysiol. 2007;18(3):329-31. https://doi.org/10.1111/j.1540-8167.2006.00686.x

5. Patel P, Krishnan K, Saha S, Trohman RG. Novel implantable cardioverter-defibrillator lead placement in a patient with a prosthetic tricuspid valve. J Innov Card Rhythm Manag. 2017;8(11):2894-7. https://doi.org/10.19102/icrm.2017.081103

6. Fadel BM, Di Salvo G. Metal through metal pacing lead across a mechanical tricuspid valve. J Cardiovasc Med. 2017;18(9):698-9. https://doi.org/10.2459/JCM.0b013e32835ec4bf

7. Rojas SCF, Schurmann PA, Rodríguez-Mañero M, Lustgarten D, Valderrábano M. Permanent His-bundle pacing from the right atrium in patients with prosthetic tricuspid valve. HeartRhythm Case Rep. 2019;5(5):244-6. https://doi.org/10.1016/j.hrcr.2019.01.009 